\title{
Properties of Erbium Doped Hydrogenated Amorphous Carbon Layers Fabricated by Sputtering and Plasma Assisted Chemical Vapor Deposition
}

\author{
V. Prajzler, Z. Burian, V. Jeřábek, I. Hüttel, J. Špirková, J. Gurovič, J. Oswald, J. Zavadil, \\ V. Peřrina \\ We report about properties of carbon layers doped with $\mathrm{Er}^{3+}$ ions fabricated by Plasma Assisted Chemical Vapor Deposition (PACVD) and \\ by sputtering on silicon or glass substrates. The structure of the samples was characterized by X-ray diffraction and their composition \\ was determined by Rutherford Backscattering Spectroscopy and Elastic Recoil Detection Analysis. The Absorbance spectrum was taken \\ in the spectral range from $400 \mathrm{~nm}$ to $600 \mathrm{~nm}$. Photoluminescence spectra were obtained using two types of Ar laser $\left(\lambda_{\text {ex }}=514.5 \mathrm{~nm}\right.$, \\ $\left.\lambda_{\text {ex }}=488 \mathrm{~nm}\right)$ and also using a semiconductor laser $\left(\lambda_{\text {ex }}=980 \mathrm{~nm}\right)$. Samples fabricated by magnetron sputtering exhibited typical emission \\ at $1530 \mathrm{~nm}$ when pumped at $514.5 \mathrm{~nm}$.
}

Keywords: carbon layers, Erbium, PACVD, sputtering, photoluminescence

\section{Introduction}

Carbon thin films have attracted the attention of various investigators due to their unique optical, electrical and mechanical properties [1]. Various deposition techniques and processes such as Plasma Enhanced Chemical Vapor Deposition (PECVD), sputter deposition etc., have been employed to deposit carbon films [2, 3]. Research on the deposition of carbon layers is mainly focused on the fabrication of diamond-like carbon (DLC) or carbon nanotubes. Our study deals with the development of carbon layers, which should have good optical properties (low optical losses, suitable refractive indices, high photoluminescence efficiency) for potential application in integrated optics. [4] and [5] have shown that it is possible to prepare carbon planar waveguides with attenuation lower than $1 \mathrm{~dB} \cdot \mathrm{cm}^{-1}$. Low optical losses of the optical materials are one of the most important preconditions for using this material in integrated optics and for doping it with active ions such as erbium.

$\mathrm{Er}^{3+}$-doped optical materials are candidates for fabricating optical amplifiers or lasers operating at $1530 \mathrm{~nm}[6$, 7, 8], due to $\mathrm{Er}^{3+}$ intra-4f emission, which corresponds to ${ }^{4} \mathrm{I}_{13 / 2} \rightarrow{ }^{4} \mathrm{I}_{15 / 2}$ transition. This wavelength is commonly used in telecommunication system, due to the fact that it corresponds to the low loss window of silica-based optical fibers.

The only papers analyzing carbon layers containing erbium ions are by Hüttel et al. [9, 10, 11], by Baranov [12] and by Speranza [13]. The articles report on fabricating erbium doped carbon layers by using magnetron sputtering on a silicon substrate. Baranov and Speranza used a graphite target partially covered with pieces of metallic erbium, and deposition was performed in a gas mixture of argon and $\mathrm{C}_{6} \mathrm{H}_{12}$ at a pressure of about $10^{-3} \mathrm{~Pa}$. The carbon layers had an amorphous structure with $\mathrm{sp}^{2}$ arrangement in which the Er concentration varied from $0.15 \%$ to $0.8 \%$. They observed photoluminescence due to the $\mathrm{Er}^{3+}$ transition ${ }^{2} \mathrm{H}_{11 / 2} \rightarrow{ }^{4} \mathrm{I}_{15 / 2}$ only in the sample with the highest amount of erbium.
In this paper we will report on our attempts to fabricate carbon layers with erbium content higher than those in the papers mentioned above.

\section{Measurements}

The structure of the deposited carbon layers was studied by XRD (X-ray diffraction). The compositions of the fabricated samples were determined using nuclear chemical analyses such as Rutherford Backscattering Spectroscopy (RBS) and Elastic Recoil Detection Analysis (ERDA). The amounts of erbium ions were checked by RBS using both $2.4 \mathrm{MeV}$ protons and 2.2 MeV alpha particles. The RBS and ERDA spectra were evaluated by GISA3 [18] and SIMNRA [19] code, respectively.

The absorbance spectra of the samples were taken in the spectral region from $400 \mathrm{~nm}$ to $600 \mathrm{~nm}$ at room temperature. A tungsten lamp and MDR 23 monochromator were used as a light source, and the light transmitted through the samples was detected by the pyro-detector. The photoluminescence measurement was carried out at three excitation wavelengths:

- An ILA-120 Ar laser operating at $\lambda_{\mathrm{ex}}=488 \mathrm{~nm}, \mathrm{E}_{\mathrm{ex}}=100 \mathrm{~mW}$, (300 K).

- Ar lasers operating at $\lambda_{\mathrm{ex}}=514.5 \mathrm{~nm}, \mathrm{E}_{\mathrm{ex}}=300 \mathrm{~mW},(4 \mathrm{~K})$.

- A semiconductor laser P4300 operating at $\lambda_{\mathrm{ex}}=980 \mathrm{~nm}$, $\mathrm{E}_{\mathrm{ex}}=500 \mathrm{~mW},(300 \mathrm{~K})$.

The FEU62 photocell was used for detecting the wavelength from 500 to $1000 \mathrm{~nm}$, while a Ge detector was used for the wavelength from $1000 \mathrm{~nm}$ to $1600 \mathrm{~nm}$.

\section{Sample fabrication and results}

Erbium containing carbon thin films were deposited using three different procedures:

- sputtering from carbon targets with built-in metallic erbium, 
- PACVD growth of carbon thin films from a gas mixture ( $\mathrm{H}_{2}+\mathrm{Ar}+$ erbium isopropoxide or $\mathrm{CH}_{4}+$ Erbium tris),

- magnetron sputtering placing metallic erbium on the carbon target.

The structures of the deposited carbon layers were then investigated by XRD (X-ray diffraction) and it was found that all of them were amorphous.

\subsection{Growth of erbium doped carbon thin films using sputtering}

The first procedure for depositing erbium doped carbon thin films was sputtering using a carbon (99.8\%) target that contained pieces of metallic erbium. The target was made by pressing milled graphite and erbium metal $(7 \mathrm{~g}$ $\mathrm{C}+0.8 \mathrm{~g}$ Er) applying different pressures $\left(100 \mathrm{MPa} \cdot \mathrm{cm}^{-2}\right.$ and $\left.200 \mathrm{MPa} \cdot \mathrm{cm}^{-2}\right)$. The final targets were $5 \mathrm{~cm}$ in diameter. Deposition was performed in an Ar atmosphere at a pressure of $12 \mathrm{~Pa}$ for $20 \mathrm{~min}$. Voltage on the grounded electrodes was $-75 \mathrm{~V}$ and the distance of the electrodes was $3 \mathrm{~cm}$. A schema of the experimental set-up is shown in Fig. 1.
The composition of the carbon layers determined by a nuclear chemical analysis as RBS and ERDA is given in Table 1. The actual content of erbium ions depends on the fabrication parameters, and the maximum amount obtained after optimization was 0.02 at $\%$. However, this content was still too low for photoluminescence at $1530 \mathrm{~nm}$.

\subsection{Growth of erbium doped carbon thin films using PACVD}

Here "Erbium isopropoxide" $\left(\mathrm{C}_{9} \mathrm{H}_{21} \mathrm{ErO}_{3}\right)$ was used for the first time as the erbium source. The fabrication process was based on modifying the reactor, as shown in Fig. 2 (compare with Fig. 1). The deposition of erbium doped carbon layers was carried out using methane (flow of $50 \mathrm{~cm}^{3} \cdot \mathrm{min}^{-1}$ ) and argon (flow of $30 \mathrm{~cm}^{3} \cdot \mathrm{min}^{-1}$ ). The erbium isopropoxide (Sigma-Aldrich) vapor was added into this gas mixture at a temperature from $240{ }^{\circ} \mathrm{C}$ to $260^{\circ} \mathrm{C}$ and injected into the reactor by flow of methane and argon. The bias applied at one of the electrodes was $-100 \mathrm{~V}$ and the power density was from $0.31 \mathrm{~W} \cdot \mathrm{cm}^{-2}$ to $0.35 \mathrm{~W} \cdot \mathrm{cm}^{-2}$. The deposition rate was in the

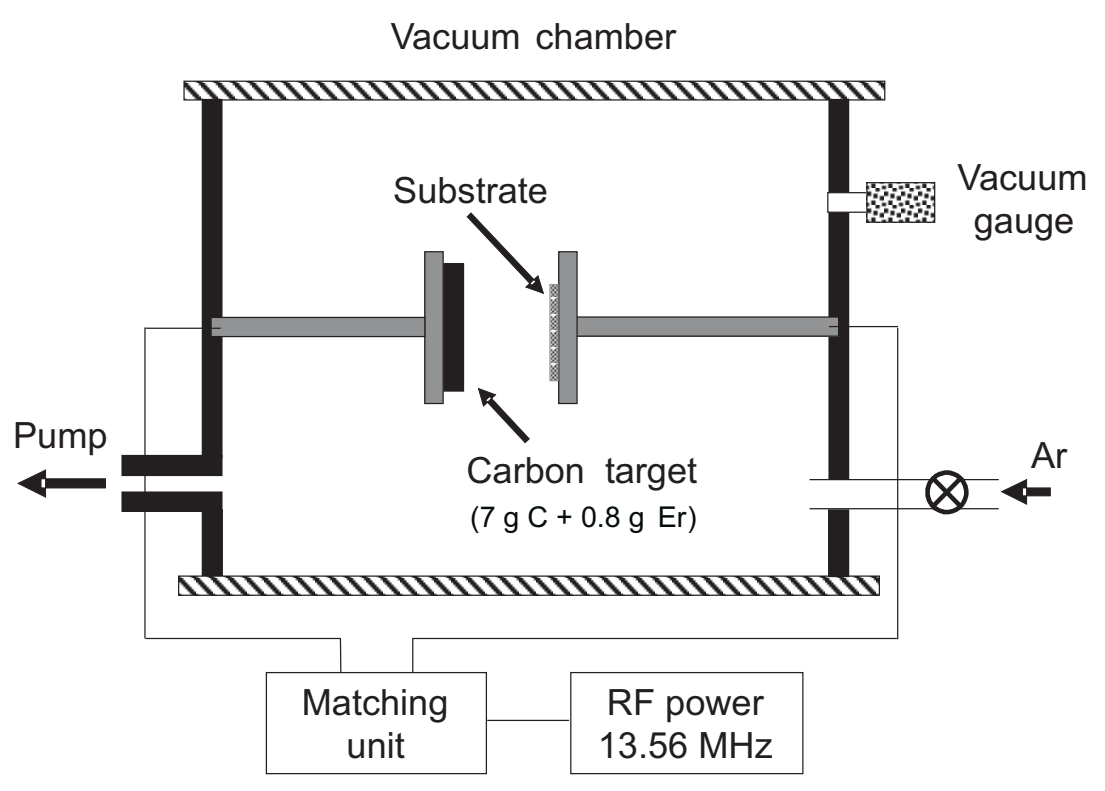

Fig. 1: Schema of the sputtering set-up (see above)

Table 1: Composition of erbium-doped carbon samples as determined by Rutherford Backscattering Analysis and Elastic Recoil Detection Analysis

\begin{tabular}{|c|c|c|c|c|}
\hline \multirow[t]{2}{*}{ Methods used for fabrication of carbon layers } & $\mathrm{C}$ & $\mathrm{H}$ & $\mathrm{O}$ & Er \\
\hline & (at \%) & (at \%) & (at \%) & $($ at $\%)$ \\
\hline Growth of erbium doped carbon thin films using sputtering ( $7 \mathrm{~g} \mathrm{C}+0.8 \mathrm{~g}$ Er) & 52 & 45 & 3 & 0.02 \\
\hline $\begin{array}{l}\text { Growth of erbium doped carbon thin films using PACVD } \\
\left(\mathrm{CH}_{4}+\mathrm{Ar}+\text { "erbium isopropoxide") }\right.\end{array}$ & 65 & 32 & 3 & 0 \\
\hline $\begin{array}{l}\text { Growth of erbium doped carbon thin films using PACVD } \\
\left(\mathrm{CH}_{4}+\text { "erbium tris") - position } 1^{*}\right.\end{array}$ & 51 & 27 & 15 & 8.7 \\
\hline $\begin{array}{l}\text { Growth of erbium doped carbon thin films using PACVD } \\
\left(\mathrm{CH}_{4}+\text { "erbium tris") - position } 2^{*}\right.\end{array}$ & 61 & 40 & 5 & 0.012 \\
\hline Growth of erbium and ytterbium doped carbon thin films using magnetron sputtering & 73 & 23 & 4 & $0.2-20 * *$ \\
\hline
\end{tabular}

* For more details see Fig. 3

** Depending on Er or Er+Yb powder laid onto the top of the carbon target (see Table 2) 


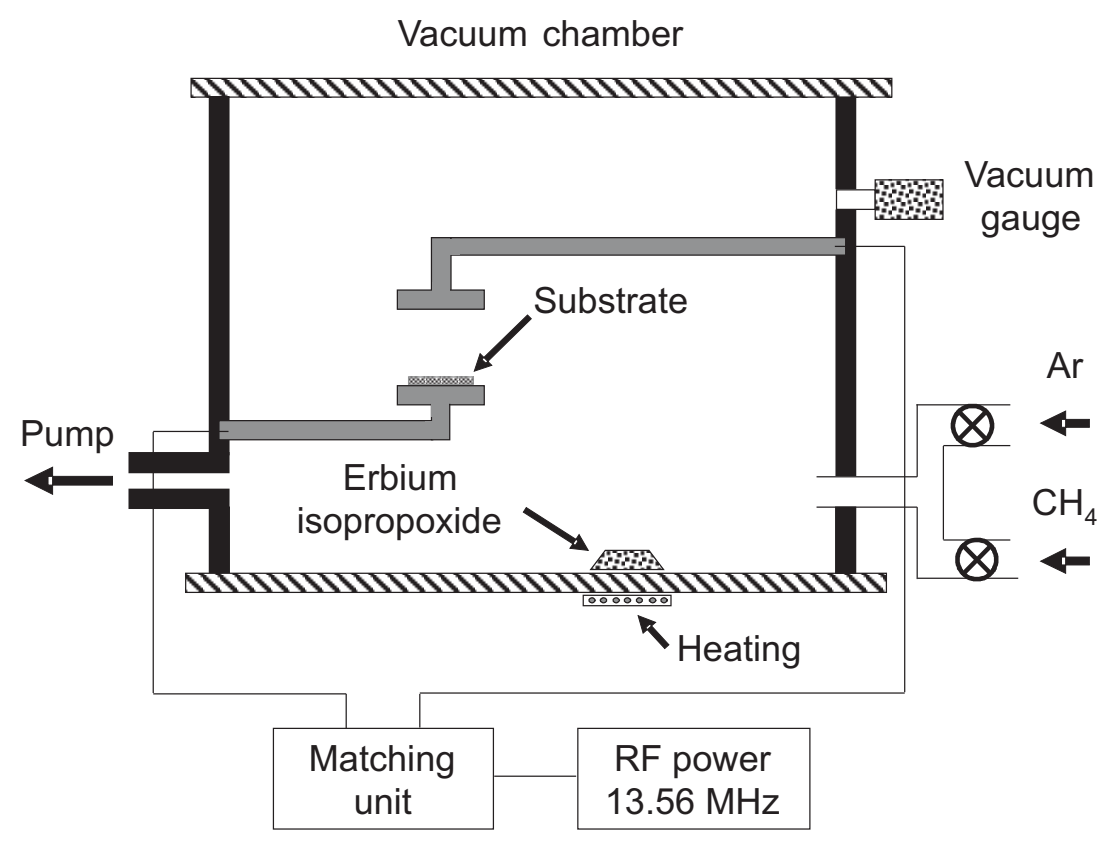

Fig. 2: Schema of the PACVD set-up used for depositing of carbon layers from methane and "erbium isopropoxide"

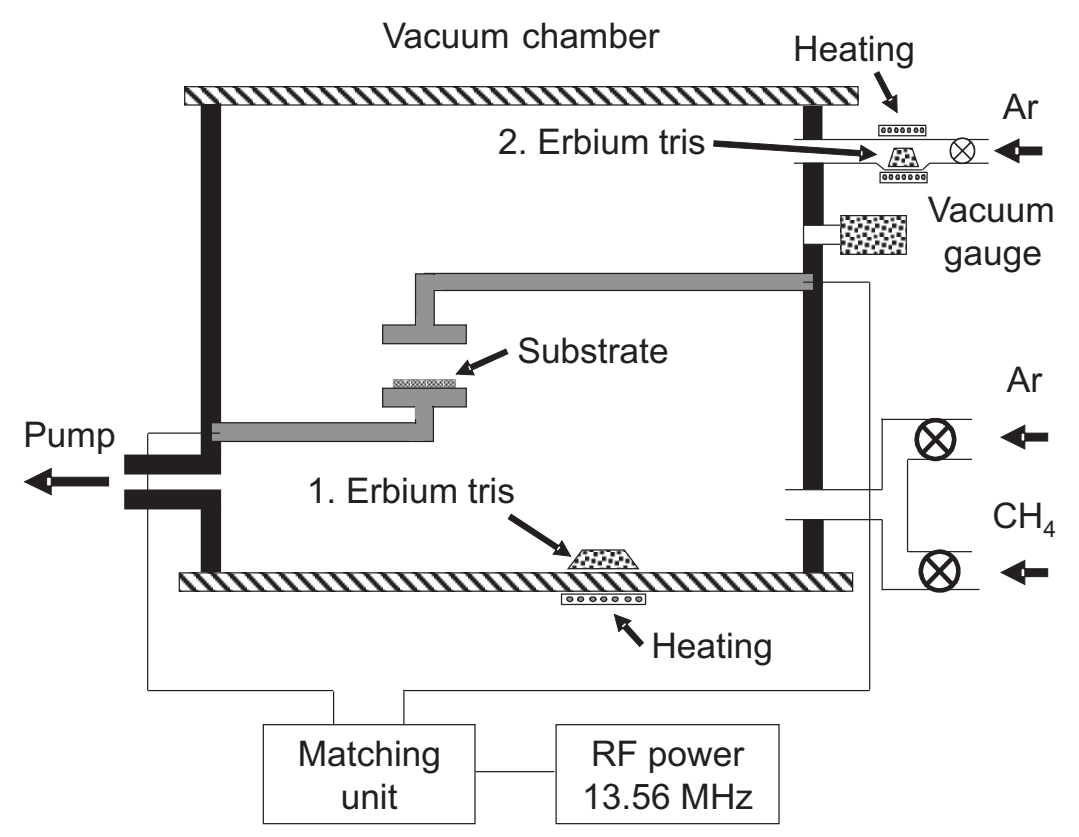

Fig. 3: Schema of the PACVD set-up used for deposition of carbon layers from methane and "erbium tris". For the erbium precursor two positions (1. and 2.) were experimentally evaluated.

range from $20 \mathrm{~nm} \cdot \mathrm{min}^{-1}$ to $22 \mathrm{~nm} \cdot \mathrm{min}^{-1}$. The temperature of the silicon substrates varied from $50{ }^{\circ} \mathrm{C}$ to $100{ }^{\circ} \mathrm{C}$.

Because the deposited samples did not contain erbium even after optimization (for more details see Table 1), another erbium source had to be searched for. Chryssou and Pitt [16] reported the fabrication of erbium doped $\mathrm{Al}_{2} \mathrm{O}_{3}$ layers using PACVD. They used "Erbium tris" (Er(thd) $)_{3}$ ) as an erbium source and the fabricated samples had photoluminescence at $1530 \mathrm{~nm}$ even at room temperature. Therefore it was decided to fabricate carbon layers doped with erbium using "Erbium tris" ([Tris (2,2,6,6-tetramethyl-3,5-heptanedionate)] $\operatorname{Er}(+I I I))$, (Sigma-Aldrich) as a source.
Deposition was carried out using methane (flow of $50 \mathrm{~cm}^{3} \cdot \mathrm{min}^{-1}$ ). "Erbium tris" vapor was produced at temperatures from $130{ }^{\circ} \mathrm{C}$ to $160{ }^{\circ} \mathrm{C}$, and it was always mixed with methane. There were two ways to insert the "Erbium tris" into the vacuum chamber (Fig. 3). When the "Erbium tris" was in position (1) the concentration of erbium ions in the deposited carbon layers was as high as 9 at \%. When the "Erbium tris" was in position (2) the erbium concentration was always lower, reaching a maximum of 0.012 at \% (see Table 1 ).

Fig. 4 shows the photoluminescence spectrum of the carbon layer fabricated by PACVD. The bands at wavelength $582 \mathrm{~nm}$ and $645 \mathrm{~nm}$ come from the carbon layers themselves 


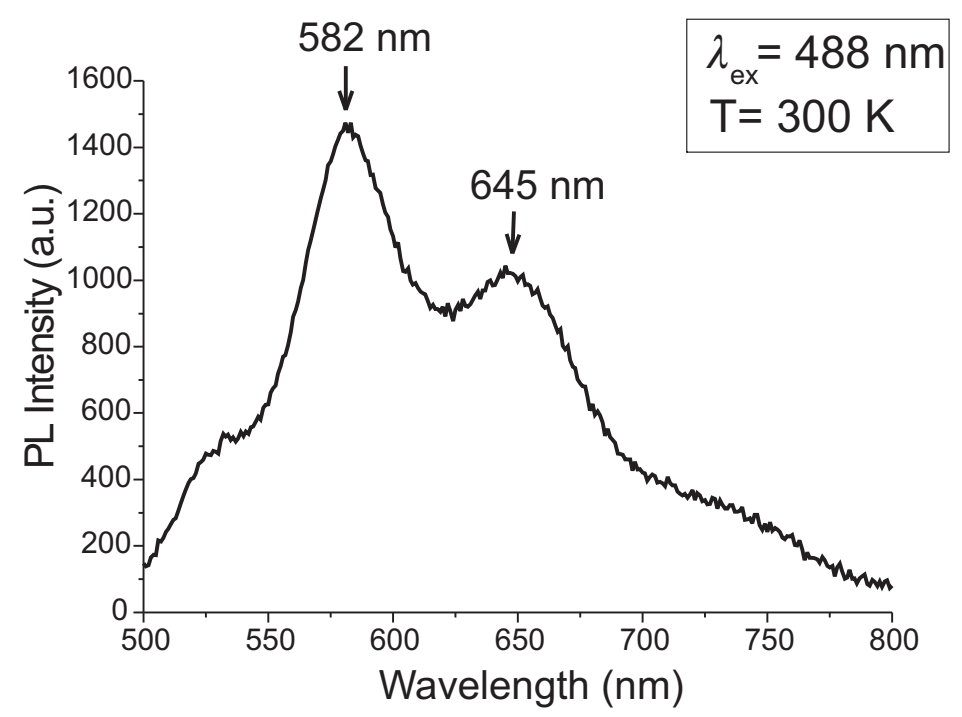

Fig. 4: Photoluminescence spectrum of a carbon layer fabricated by PACVD

(similar photoluminescence had already been reported in [17]). Obviously, photoluminescence at $1530 \mathrm{~nm}$ (PL band $\left.{ }^{4} \mathrm{I}_{15 / 2} \rightarrow{ }^{4} \mathrm{I}_{11 / 2}\right)$ did not occur. The probable reason is that the samples contained $\mathrm{OH}$ groups (see Table 1) due to the gas source applied for the growing process (methane as the hydrogen source, oxygen residual contamination). OH impurities are known to quench Er luminescence.

\subsection{Growth of erbium doped carbon thin films using magnetron sputtering}

The carbon layers were deposited by RF magnetron sputtering (Balzers Pfeiffer PLS 160) using a carbon target of $99.9999 \%$ purity. The RF magnetron sputtering set-up is depicted in Fig. 5. The typical growth parameters were: deposition temperature $300 \mathrm{~K}, \mathrm{Ar}$ or $\mathrm{Ar}+\mathrm{CH}_{4}$ gas mixture, total gas pressure from $1 \mathrm{~Pa}$ to $4 \mathrm{~Pa}$, and the growing time ranged from $30 \mathrm{~min}$ to $4 \mathrm{hrs}$, with power from $50 \mathrm{~W}$ to $150 \mathrm{~W}$ $(13.56 \mathrm{MHz})$. For $\mathrm{Er}^{3+}$ doping into the carbon samples, powder of $\operatorname{Er}(99.9 \%$ purity) was placed on top of the carbon target.

The RBS analyses and also the ERDA analyses of the deposited layers proved that the samples contained carbon, argon, oxygen, hydrogen and erbium (see Tab. 1). The list of carbon samples and the relevant content of erbium or erbium ions is given in Table 2. The amount of incorporated erbium ions differed depending on the area of the target covered by erbium powder placed on the target, and also depending on the erosion area represented by the part of the surface covered by the erbium ions. The samples had a total erbium content ranging from 1 at $\%$ to 17.1 at $\%$. The highest concentration $(17.1$ at $\%)$ of erbium was found in the sample doped using $1.0004 \mathrm{~g}$ of erbium powder.

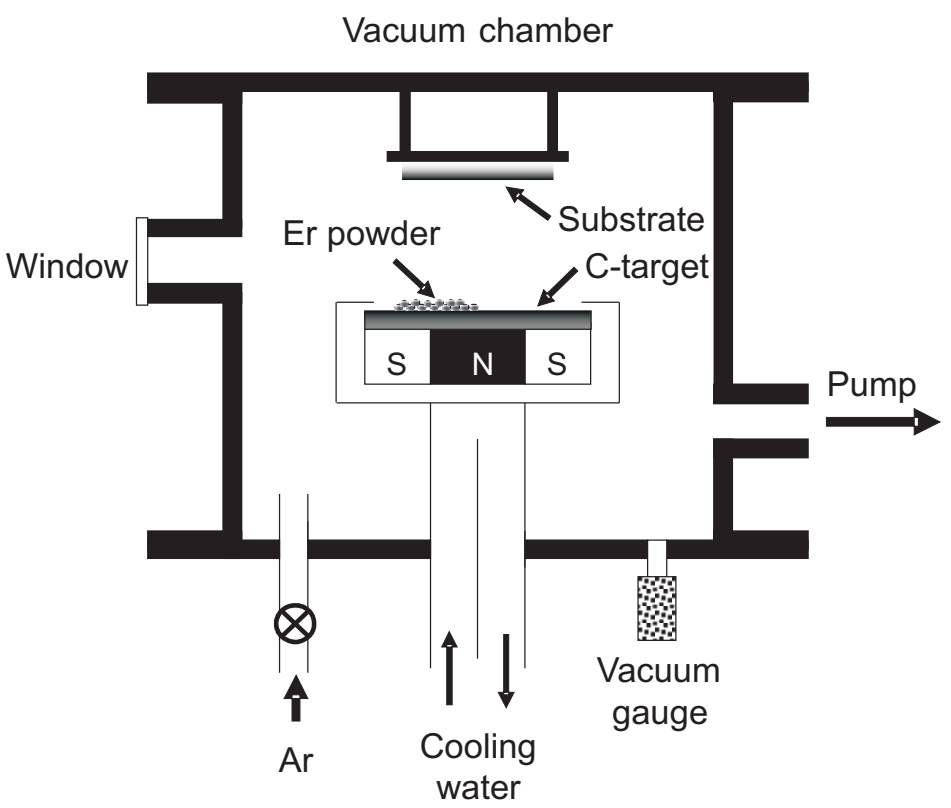

Fig. 5: The schema of magnetron sputtering set-up 
Table 2: Composition of erbium-doped carbon samples fabricated by magnetron sputtering, showing the relations between the amounts of erbium used for doping and the actual concentrations of erbium found in the doped samples

\begin{tabular}{|c|l|c|}
\hline Samples & \multicolumn{1}{|c|}{ Doping } & $\begin{array}{c}\text { Er } \\
(\text { at } \%)\end{array}$ \\
\hline$\# 1$ & Reference sample $*$ & $\ldots$ \\
\hline$\# 2$ & Er $\mathrm{m}_{\mathrm{Er}}=0.0011 \mathrm{~g} * *$ & 1.2 \\
\hline$\# 3$ & Er $\mathrm{m}_{\mathrm{Er}}=0.0012 \mathrm{~g} * *$ & 1.7 \\
\hline$\# 4$ & Er $\mathrm{m}_{\mathrm{Er}}=0.0106 \mathrm{~g} * *$ & 4.8 \\
\hline$\# 5$ & Er $\mathrm{m}_{\mathrm{Er}}=0.0104 \mathrm{~g} * *$ & 6.0 \\
\hline$\# 6$ & Er $\mathrm{m}_{\mathrm{Er}}=0.5004 \mathrm{~g} * *$ & 8.4 \\
\hline$\# 7$ & Er $\mathrm{m}_{\mathrm{Er}}=0.5004 \mathrm{~g} * *$ & 9.0 \\
\hline$\# 8$ & Er $\mathrm{m}_{\mathrm{Er}}=0.5004 \mathrm{~g} * *$ & 12.5 \\
\hline$\# 9$ & Er $\mathrm{m}_{\mathrm{Er}}=1.0004 \mathrm{~g} * *$ & 15.7 \\
\hline$\# 10$ & Er $\mathrm{m}_{\mathrm{Er}}=1.0004 \mathrm{~g} * *$ & 17.1 \\
\hline
\end{tabular}

* Sample without Er doping

** weight of Er powder placed on top of the carbon target

The absorbance spectrum of erbium doped carbon layers fabricated by magnetron sputtering is given in Fig. 6. This figure shows typical strong ${ }^{2} \mathrm{H}_{11 / 2}(523 \mathrm{~nm})$ transitions, which correspond to optical materials doped with erbium ions. Other $\mathrm{Er}^{3+}$ transitions ${ }^{4} \mathrm{~F}_{11 / 2}(451 \mathrm{~nm})$ and ${ }^{4} \mathrm{~F}_{7 / 2}(490 \mathrm{~nm})$ are not so strong, and transitions ${ }^{2} \mathrm{H}_{9 / 2}(405 \mathrm{~nm}),{ }^{4} \mathrm{~F}_{3 / 2}(441 \mathrm{~nm})$ and ${ }^{4} \mathrm{~S}_{3 / 2}(539 \mathrm{~nm})$ are almost hidden in the background.

Photoluminescence spectra of erbium doped carbon layers fabricated by magnetron sputtering are shown in Fig. 7 and Fig. 8. The spectrum excited by an Ar laser at very low temperature $\left(\lambda_{\text {ex }}=514.5 \mathrm{~nm}\right.$, temperature $4 \mathrm{~K}$ ) is given in Fig. 7 and shows quite well the typical photoluminescence bands attributed to the erbium transition ${ }^{4} \mathrm{I}_{13 / 2} \rightarrow{ }^{4} \mathrm{I}_{15 / 2}$. Fig. 8 shows the spectrum obtained by optical pumping at $980 \mathrm{~nm}$ at room temperature. Obviously, the peak coming from the erbium ${ }^{4} \mathrm{I}_{13 / 2} \rightarrow{ }^{4} \mathrm{I}_{15 / 2}$ transition is very weak but it is still there, as can be seen from the comparison with the PL spectrum of the reference sample given in the same figure.

The intensities of the emission bands in the $1530 \mathrm{~nm}$ region did not show any evidence of being connected with the actual concentration of $\mathrm{Er}^{3+}$ in the samples (see Table 2). The intensities are very low, so a small increase would be difficult to recognize. However, our opinion is that the higher concentration of $\mathrm{Er}^{3+}$ resulted in the formation of clusters that, due to pair interactions, would in fact have a counterproductive concentration quenching effect.

\section{Conclusion}

We report on carbon layers doped with erbium ions deposited by sputtering, by PACVD and by magnetron sputtering onto a silicon or glass substrate. The fabricated samples had an amorphous structure.

When the carbon samples were fabricated by sputtering the content of erbium ions was too low to reveal the photoluminescence at $1530 \mathrm{~nm}$. Carbon layers fabricated by PACVD using a $\mathrm{CH}_{4}+\mathrm{Ar}+$ "erbium isopropoxide" gas mixture did not even contain erbium. Erbium doped carbon samples fabricated by PACVD using "Erbium tris" as erbium source contained erbium ions but no photoluminescence at $1530 \mathrm{~nm}$ was observed. The main reason could be that the carbon samples contained oxygen and hydrogen. $\mathrm{OH}$ impurities are known to be a strong quencher of Er luminescence.

The most successful method for fabricating erbium doped carbon layers was magnetron sputtering. The content of erbium ions in the carbon samples was controlled by the amount of erbium powder placed on the carbon target. Under optical pumping at $514.5 \mathrm{~nm}(4 \mathrm{~K})$ the typical photoluminescence emission due to the transition of ${ }^{4} \mathrm{I}_{13 / 2} \rightarrow{ }^{4} \mathrm{I}_{15 / 2}$ was observed. This emission, though rather weak, was observed even at room temperature when generated by optical pumping at $980 \mathrm{~nm}$.

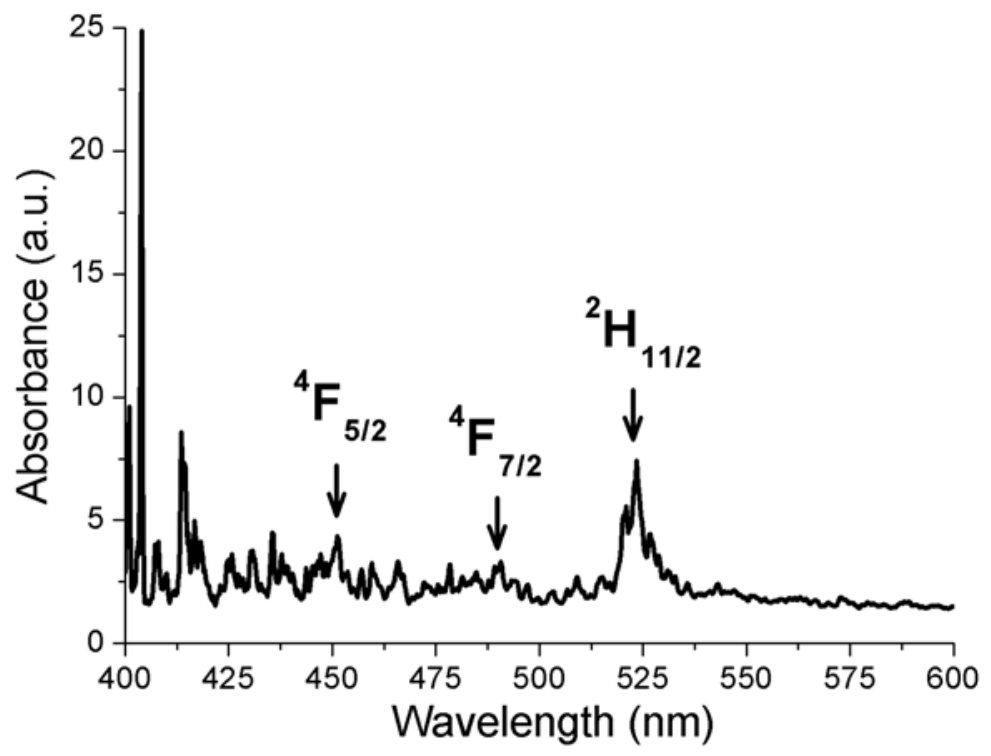

Fig. 6: Absorbance spectra of $\mathrm{Er}^{3+}$ doped carbon layers 


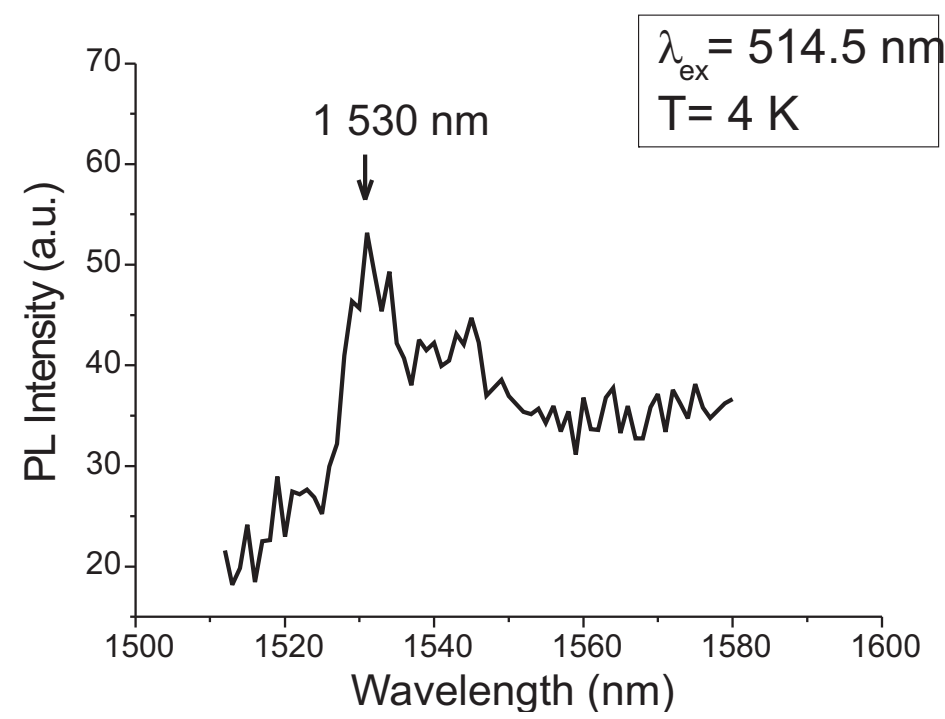

Fig. 7: Photoluminescence spectra of erbium doped carbon layers

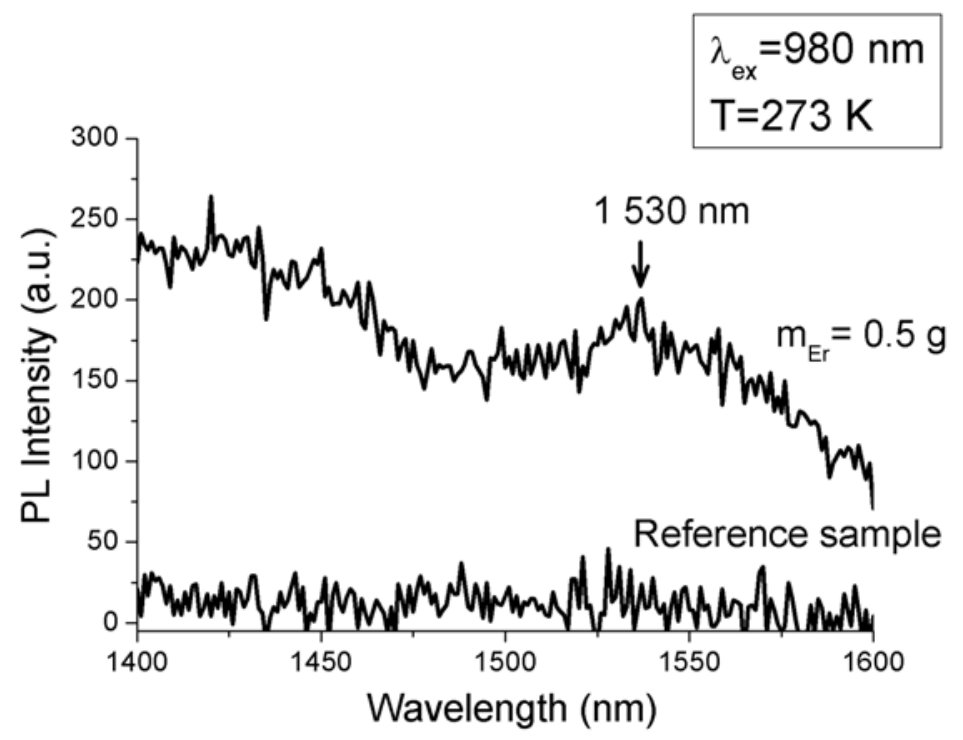

Fig. 8: Photoluminescence spectra of erbium doped carbon layers

\section{Acknowledgments}

Our research is supported by the Grant Agency of the Czech Republic under grant number 102/06/0424 and by research program MSM6840770014 of the Czech Technical University in Prague.

\section{References}

[1] Mandel, T., Frischholz, M., Helbig, R., Birkle, S., Hammerschmidt, A.: Electrical and optical- Properties of Heterostructures Made from Diamond-Like Carbon Layers on Crystalline Silicon. Applied Surface Science, Vol. 65 (1993), No. 6 , p. 795-799.

[2] Smith, S. M., Voight, S. A., Tompkins, H., Hooper, A., Talin, A. A., Vella, J.: Nitrogen-Doped Plasma Enhanced Chemical Vapor Deposited (PECVD) Amorphous Carbon: Processes and Properties. Thin Solid Films, Vol. 398 (2001), p. 163-169.
[3] Kusano, Y., Evetts, J. E., Somekh, R. E., Hutchings I. M.: Properties of Carbon Nitride Films Deposited by Magnetron Sputtering. Thin Solid Films, Vol. 332 (1998), No. 1-2, p. 56-61.

[4] Hüttel, I., Gurovič, J., Černý, F., Pospíšil, J.: Carbon and Carbon Nitride Planar Waveguides on Silicon Substrates. Diamond and Related Materials, Vol. 8 (1999), No. 2-5, p. 628-630.

[5] Hüttel, I., Černý, F., Gurovič, J., Chomát, M., Matějec, V.: Thin Carbon Nitride Films for Integrated Optical Chemical Sensors. SPIE Vol. 3858 (1999), p. 210-217.

[6] Polman, A.: Erbium Implanted Thin Film Photonic Materials. Journal of Applied Physics, Vol. 82 (1997), p. 1-39.

[7] Kenyon, A. J.: Recent Developments in Rare-Earth Doped Materials for Optoelectronics. Progress in Quantum Electronics, Vol. 26 (2002), No. 4-5, p. 225-284. 
[8] van den Hoven, G. N., Snoeks, E., Polman, A., Vanuffelen, J. W. M., Oei, Y. S., Smit, M. K.: Photoluminesce Characterization of Er-Implanted $\mathrm{Al}_{2} \mathrm{O}_{3}$ Films. Applied Physics Letters, Vol. 62 (1993), No. 24, p. 3065-3067.

[9] Prajzler, V., Hüttel, I., Nekvindová, P., Schröfel, J., Macková, A., Gurovič, J.: Erbium Doping into Thin Carbon Optical Layers. Thin Solid Films, Vol. 433 (2003), No. 1-2, p. 363-366.

[10] Prajzler, V., Hüttel, I., Schröfel, J., Nekvindová, P., Gurovič, J., Macková, A.: Carbon Layers for Integrated Optics. Photonics, Devices, and Systems II, SPIE (2002), p. 342-347.

[11] Prajzler, V., Hüttel, I., Špirková, J., Oswald, J., Peřina, V., Machovič, V., Jeřábek, V.: Properties of Sputtered Carbon Layers Containing Erbium and Ytterbium Ions. Electronic Devices and Systems EDS2006, IMAPS CS, (2006), p. 403-408.

[12] Baranov, A. M., Sleptsov, V. V., Nefedov, A. A., Varfolomeev, A. E., Fanchenko, S. S., Calliari, L. Speranza, G., Ferrari, M., Chiasera, A.: Erbium Photoluminescence in Hydrogenated Amorphous Carbon. Physics Status Solidy b, Vol. 234 (2002), No. 2, p. R1-R3.

[13] Speranza, G., Calliari, L., Ferrari, M., Chiasera, A., Ngoc, K. T., Baranov, A. M., Sleptsov, V. V., Nefedov, A. A., Varfolomeev, A. E.. Fanchenko, S. S.: Erbium Doped Thin Amorphous Carbon Films Prepared by Mixed CVD Sputtering. Applied Surface Science, Vol. 238 (2004), p. 117-120.

[14] Saarilahti, J., Rauhala, E.: Interactive Personal-Computer Data-Analysis of Ion Backscattering Spectra. Nuclear Instruments \& Methods in Physics Research Section B-Beam Interactions with Materials and Atoms, Vol. 64 (1992), No. 1-4, p. 734-738.

[15] Mayer, M.: Simnra Users Guide, Institut für Plasmaphysik, 1998.

[16] Chryssou, C. E., Pitt, C. W.: Er(3+)-Doped $\mathrm{Al}_{2} \mathrm{O}_{3}$ Thin Films by Plasma-Enhanced Chemical Vapor Deposition (PECVD) Exhibiting a $55 \mathrm{~nm}$ Optical Bandwidth. IEEE Journal of Quantum Electronics, Vol. 34 (1998), No. 2, p. 282-285.

[17] Rusli, Amaratunga G. A. J., Silva, S. R. P.: Photoluminescence in Amorphous Carbon Thin Films and its Relation to the Microscopic Properties. Thin Solid Films, Vol. 270 (1995), No. 1-2, p. 160-164.

Ing. Václav Prajzler, Ph.D.

e-mail: xPrajzlv@feld.cvut.cz
Doc. Ing. Zdeněk Burian, CSc. e-mail:Burian@fel.cvut.cz

Ing. Vitězslav Jeřábek, CSc. e-mail: jerabek@fel.cvut.cz

Department of Microelectronics

Czech Technical University in Prague

Faculty of Electrical Engineering

Technická 2

16627 Prague, Czech Republic

Doc. Ing. Ivan Hüttel, DrSc.

e-mail: Ivan.Huttel@vscht.cz

RNDr. Jarmila Špirková, CSc.

e-mail: Jarmila.Spirkova@vscht.cz

Institute of Chemical Technology

Technická 5

16627 Prague, Czech Republic

Ing. Ján Gurovič

e-mail: Jan.Gurovic@fs.cvut.cz

Department of Physics

Czech Technical University in Prague

Faculty of Mechanical Engineering

Technická 4

16607 Prague, Czech Republic

Ing. Jiř́i Oswald, CSc.

e-mail: Oswald@fzu.cz

Institute of Physics

Czech Academy of Sciences

Cukrovarnická 10

16253 Prague, Czech Republic

RNDr. Jiří Zavadil, CSc.

e-mail: Zavadil@ure.cas.cz

Institute of Radio Engineering and Electronics Academy of Sciences

Chaberská 57

18251 Prague, Czech Republic

Vratislav Peřina

e-mail: Perina@ujf.cas.cz

Institute of Nuclear Physics

Czech Academy of Sciences

25068 Řež near Prague, Czech Republic 